\title{
ASO Visual Abstract: Impact of Gemcitabine Plus S1 Neoadjuvant Chemotherapy on Borderline Resectable Perihilar Cholangiocarcinoma
}

Ryusei Matsuyama, MD, Ryutaro Mori, MD, Yohei Ota, MD, Yuki Homma, MD, Yasuhiro Yabusita, MD, Seigo Hiratani, MD, Takashi Murakami, MD, Yu Sawada, MD, Kentaro Miyake, MD, Yasuhiro Shimizu, MD, Takafumi Kumamoto, MD, and Itaru Endo, MD

Department of Gastroenterological Surgery, Yokohama City University Graduate School of Medicine, Yokohama, Japan

In a single-arm, phase 2 study, neoadjuvant chemotherapy (NAC) with gemcitabine plus S1, repeated every 21 days, was administered for three cycles to patients with borderline resectable (BR) perihilar cholangiocarcinoma (PHC). In this study (https://doi.org/10.1245/s10434-021-11206-4), BR PHC was defined as positive for lymph node metastasis and positive for cancerous vascular invasion or Bismuth type 4 on preoperative imaging. The study enrolled 60 patients between January 2011 and December 2016. Curative-intent resection was performed for $43(71 \%)$ of the 60 patients. The median survival time was 50.1 months for the resected patients and 14.8 months for the unresected patients. The estimated 3- and 5-year survival rates were $55.8 \%$ and $36.4 \%$, respectively, for the resected patients.

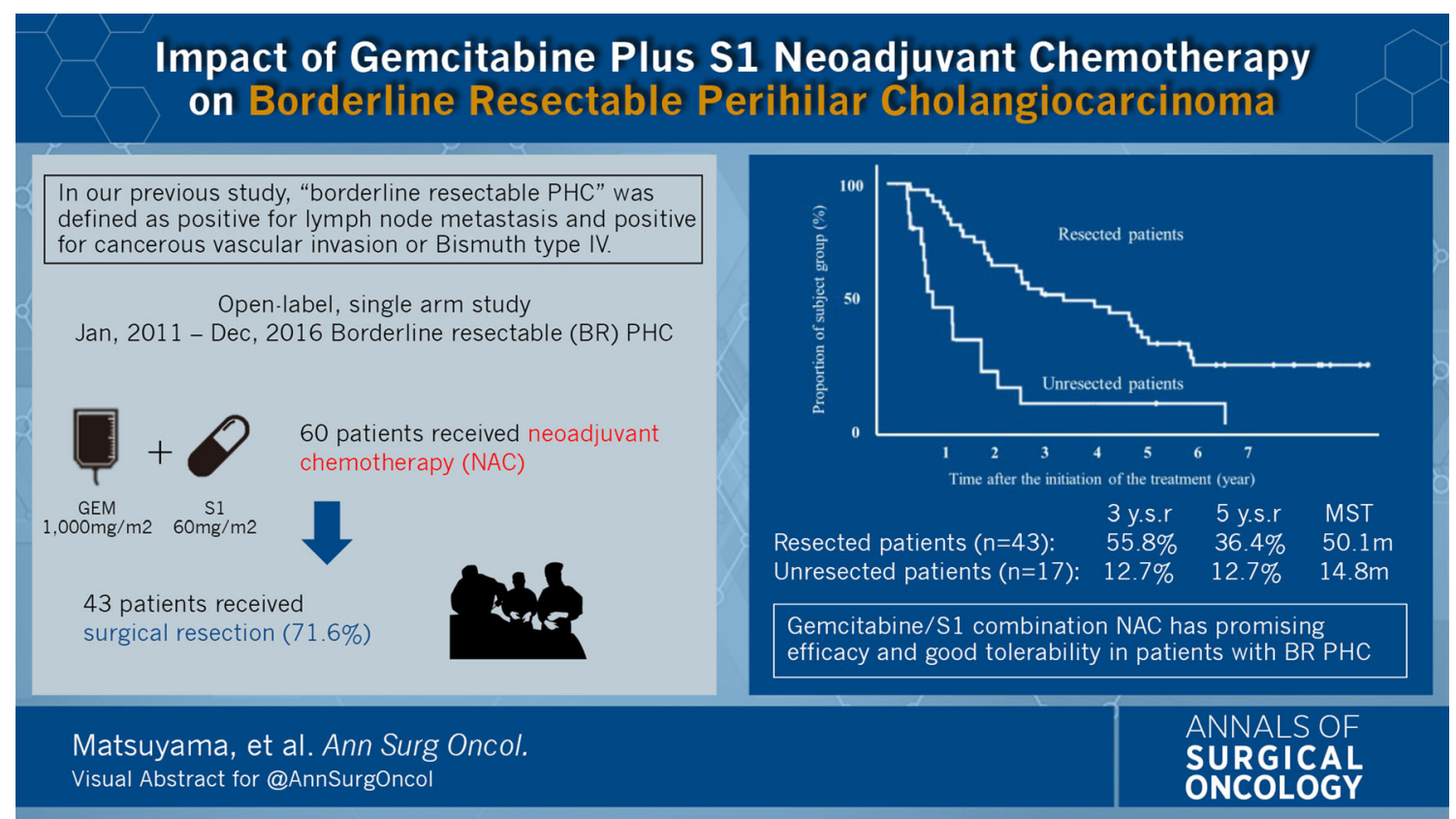

DISCLOSURE There are no conflicts of interest.

(C) Society of Surgical Oncology 2022

R. Matsuyama, MD

e-mail: ryusei@terra.dti.ne.jp
Publisher's Note Springer Nature remains neutral with regard to jurisdictional claims in published maps and institutional affiliations. 